\title{
Active Shooter Exercise Training for Nurses in Emergency Medicine
}

Paul P. Rega* and Brian N. Fink

Department of Public Health and Preventive Medicine, University of Toledo, USA

*Corresponding author: Paul P. Rega, Associate Professor of Public Health, University of Toledo, Department of Public Health and Preventive Medicine, USA, Tel: 4193834817; E-mail: Paul.Rega@utoledo.edu

Received date: Mar 23, 2016; Accepted date: Apr 28, 2016; Published date: May 5, 2016

Copyright: (C) 2016 Rega PP, et al. This is an open-access article distributed under the terms of the Creative Commons Attribution License, which permits unrestricted use, distribution, and reproduction in any medium, provided the original author and source are credited.

\section{Introduction}

The recent horrific events surrounding San Bernardino and Paris underscore the conceit that active shooter incidents must be included into the new reality of day-to-day existence in virtually every part of the world. In the United States, the incidence of active shooter events has more than doubled, comparing the period 2000-2006 with 2007-2013 [1-5]. The literature indicates that many countries share this concern [6-20]. With a recent report indicating global terror groups are planning more attacks upon the western industrialized countries, there should be no expectation that this increase in active shooter events is an aberration. Among the soft targets that remain a cause of concern for federal and state agencies is the healthcare system [21]. In fact, active shooter incidents have increased in hospitals from nine per year in 2000-2005 to 16.7 per year in 2006-2011 [1]. Granted, most of the incidents target specific individuals, but it does underscore the vulnerability of healthcare facilities, their staff and clients.

Due to certain mass shooting events in the United States, there has been a paradigm shift as to the way innocent civilians should respond to an active shooter. The current adage articulated by governmental organizations is, "Run, Hide, and Fight." However, within the healthcare system, this is rather simplistic and does not fully and completely acknowledge the roles and responsibilities of the healthcare professional, in particular, the nurse. The duty of the nurse to the patient and, by extension, the family of the patient, may run counter to the standard, well-accepted active shooter response guidelines as promulgated by federal and various law enforcement agencies. The survival instincts of the nurse to an active shooter announcement may be completely opposite to what the nurse may desire to do in order to protect the patient. This inherent conflict between the nurse's survival instincts and one's duty to one's patient oftentimes is not fully explored in most of the training programs associated with an active shooter response.

The purpose of this paper is to facilitate an exploration of the issues associated between nurse and patient when both are confronted with an active shooter situation by providing a road map and a template to assist the facilitator with developing an active shooter tabletop exercise. Emphasis will be placed upon the Emergency Department and its nurses since that is the locus of great accessibility to the public and often the site of violence $[9,13,16]$.

\section{Methods}

\section{Players}

- General patient care staff nurses

- Administrative nurses (Train-the-trainer program)

- Interdisciplinary staff and professionals
- In time, this will be the best approach

\section{Preparation}

- Multiple You-Tube videos that have been developed by diverse law enforcement agencies.

- US Department of Health and Human Services' Incorporating Active Shooter Incident Planning into Health Care Facility Emergency Operations Plans document (2).

- Institution's disaster and active shooter policies and procedures

\section{The set-up}

- Active shooter notification

- The scenario begins with the announcement over the public address system assuming that is part of the hospital policy.

- It habituates the players' senses to the announcement

- It must be stressed that the cacophony of gunfire and screams may precede any official announcements.

- Geographical relationship between shooter and nurse

Notes: At the initial exercises, it would serve everyone well to keep a distance between shooter and player so as to give the player time to choose one of the three options (i.e., Run, Hide, Fight). As more exercises are played out and both facilitators and players become acclimated to the exercise, the geographical juxtaposition between player and shooter can become closer. For example, announcement of an active shooter on the second floor in relation to the Emergency Department's location on the first floor.

\section{Nurse-player location}

- There are two general areas where Emergency Department nurses may be located at the beginning of the exercise.

- Direct patient care areas: Patient rooms

- Indirect patient care areas: Nurses' station, break room, supply room, etc.

- The potential conflict between the nurse's sense of survival and the obligation to provide for the safety and well-being of the patient is no greater than when both patient (and family) and collocated with the nurse or nurse team.

\section{Patient scenarios:}

The scenarios are of varying severity and complexity since these may be confounders that will aid or hinder a nurse's innate sense of self-preservation as the situation clarifies. Below are a number of scenarios attempting to accomplish that objective:

Chief complaint: New onset headache 
Citation: Rega PP, Fink BN (2016) Active Shooter Exercise Training for Nurses in Emergency Medicine. Adv Practice Nurs 1: 109. doi:

Page 2 of 4

- Patient: 45-year old male

- P: 86; R: 16; B/P: 126/87; SaO2: 98\%; GCS: 15

- ED elapsed time: 45 minutes

- Management: CT negative (per radiologist); LP pending

Chief complaint: Asthmatic; difficulty breathing; wheezy

- Patient: 25-year old female

- P: 96; R: 26; B/P: 136/77; SaO2: 95\% (21\%); GCS: 15

- ED elapsed time: 15 minutes

- Management: One aerosol in progress

Chief complaint: Poly-pharmacy OD

- Patient: 21-year old female

- P: 106; R: 18 (Ventilator); B/P: 96/57; SaO2: 95\% (100\%); GCS: 8

- ED elapsed time: 135 minutes

- Management: Invasive airway control, pressor support, sedation

Chief complaint: Ankle sprain (massively swollen); ambulatory capacity: $50 \%$ of normal

- Patient: 35-year old male

- P: 66; R: 16; B/P: 126/87; SaO2: 99\% (21\%); GCS: 15

- ED elapsed time: 15 minutes

- Management: Waiting to go to radiology

Chief complaint: Chest pain

- Patient: 65-year old female

- P: 106; R: 20; B/P: 166/97; SaO2: 95\% (2 L/m); GCS: 14

- ED elapsed time: 95 minutes

- Management: EKG: Non-specific changes; CXR: Negative; Enzymes. Pending; IV NTG and heparin (discomfort resolved)

Chief complaint: Fever and delirium; full code

- Patient: 85-year old female (Nursing home)

- P: 116 (AF); R: 26; B/P: 86/47; SaO2: 91\% (100\%); GCS: 10; T: $102.8 \mathrm{~F}$

- ED elapsed time: 120 minutes

- Management: Fluids, pressors, antibiotics, sedation; imaging and LP scheduled

Chief complaint: Fever, crying $\times 24$ hours (Dad and Mom present)

- Patient: 6-month old female

- P: 126; R: 26; B/P: NA; SaO2: 95\% (21\%); GCS: Awake, alert

- ED elapsed time: 25 minutes

- Management: No exam as yet; antipyretic given

Chief complaint: Foreign body right eye $(\mathrm{OD}) /$ self-diagnosis $) \times 3$ hours

- Patient: 43-year old female

- P: 76; R: 16; B/P: 106/64; SaO2: 100\% (21\%); GCS: 15; T: 98.6F; VA: $20 / 20$

- ED elapsed time: 5 minutes

- Management: No exam as yet;

Chief complaint: MVC (head-on); no seat belt; head smashed window; neck pain.

- Patient: 32-year old male

- P: 96; R: 22; B/P: 118/76; SaO2: 97\% (21\%); GCS: 13-14
- ED elapsed time: 5 minutes

- Management: No exam as yet; Backboard and collar per EMS Chief complaint: Cardiac arrest by LS; Full code

- Patient: 52-year old female

- P: Asystole; R: 2nd intubation under way; B/P: 0; SaO2: NA; GCS: 3

- ED elapsed time: 1 minute

- Management: CPR/ACLS

Chief complaint: Cardiac arrest by LS; Full code

- Patient: 42-year old male

- P: VF; R: 20 (vent); B/P: 0; SaO2: NA; GCS: 3

- ED elapsed time: 30 minutes

- Management: CPR/ACLS/ defibrillation x 3

Chief complaint: Cardiac arrest by LS; resuscitated; Hypothermia protocol

- Patient: 72-year old female

- P: 50 (paced); R: 18 (vent); B/P: 86/43; SaO2: 92\%; GCS:

- ED elapsed time: 100 minutes

- Management: CPR/ACLS/ICE

\section{Nurse's actions (Run-Hide-Fight)}

- Now in the care of the selected patient as exemplified by the cases above, the location of the shooter, the nurse-player must decide upon a course of action: Run to safety; Hide because escape is deemed too risky; and Fight should there be, at some point, confrontation with the shooter who either breeched the hiding spot or was encountered during the escape process.

- Run (considerations)

Why?

Where?

With whom?

With what (ad hoc weaponry)?

- Hide (considerations)

Why?

How will the room be blockaded? (Table 1)

Gurney**

Crash cart

Cardiac monitor

Surgical tape*

Nasal cannula*

Table 1: Select improvisational blockade items (typically found in a patient room) to prevent entry into hiding area (patient care room). * These items can be used to restrict the actions of the automatic door closer. ${ }^{* *}$ If the patient is somewhat mobile, taking him/her off the gurney and resting on the floor will allow the use of the gurney to block the entrance. 
Page 3 of 4

What preparations are being made should the shooter breech the area?

Fight (considerations)

Itemize hospital items in room that can be used as improvisational weapons. (Table 2)

To deflect shooter's aim

To inflict harm

\begin{tabular}{|l|l|}
\hline Intraosseous Needles & Suction canister \\
\hline Intravenous needles & Thoracotomy equipment \\
\hline Laryngoscopes * & Scalpels \\
\hline Endotracheal tube stylets & Ultrasound \\
\hline Flashlights * & Trauma shears \\
\hline Ophthalmoscope & Drug vials \\
\hline Otoscope & IV poles \\
\hline Sharps box & Oxygen tanks \\
\hline Backboard & Defibrillator \\
\hline Furniture (e.g., chair) & Remote control \\
\hline Cervical collars & Phone and phone cord \\
\hline Computer mouse & Towels \\
\hline Pillows & Bed linens \\
\hline Trash can & Bar soap \\
\hline Chest spreader & Splints \\
\hline
\end{tabular}

Table 2: Select improvisational weapons (typically found in a patient room) with which to attack the perpetrator once entry into hiding area (patient care room) is attempted. * These items can be broken down to many parts and each can serve as a weapon. For example, the traditional laryngoscope is made of four parts (blade, handle, and two batteries).

\section{Discussion}

The United States Department of Homeland Security, Federal Emergency Management Association (FEMA), Federal Bureau of Investigation (FBI), Assistant Secretary for Preparedness and Response (ASPR) and Department of Health and Human Services (DHHS) collaborated on incorporating active shooter planning into healthcare facility emergency operation planning. However, training is sparse, inconsistent, and, oftentimes, voluntary. In addition, the training does not acknowledge, in fine detail, the potential conflict these professionals may face when they are confronted with an immediate decision involving the saving of their own lives as well as securing the safety and well-being of their patients. This is particularly true for nurses who are most often intimately involved with their patients' care.

Each event is unique. Because of that uniqueness, there is no right or wrong answer with regard to a nurse's specific action. However, these issues need to be recognized and discussed. It's possible that through these activities such as table-top exercises, some new answers may be discovered that may mitigate some of the problems.
While this paper deals with table-top exercises, it is not the endpoint. At some point, functional exercises should be developed in order to take the lessons learned from the table-top exercises and see if they work in a realistic setting.

Incorporating active shooter scenarios in medical simulations can be accomplished in a no-threat, no-consequence environment. Regular training of nurses through simulation of typical and atypical scenarios in healthcare facilities provides experience and sharpens mental "muscle memory", thus allowing them to make wise decisions quickly during an actual active shooter incident. This is also best accomplished if done in an interdisciplinary format (i.e. nurses, physicians, PAs, respiratory technicians, etc.) with an interdisciplinary team of educators.

Therefore, in time, the design and planning of the training must include law enforcement, local public health professionals, administration and staff from the healthcare facility, and the nurses, physicians, physician assistants, and other healthcare providers. Training exercises must occur regularly throughout the year to ensure both routine practicing as well as account for change in personnel.

To sum up, active shooter incidents in healthcare facilities bring a unique set of circumstances that make it difficult to come up with one correct answer, especially in a matter of seconds. Healthcare professionals and students abide by the Hippocratic Oath. They have a responsibility to their patient, as well as to their colleagues. How they respond depends on the situation and their experience. With training comes experience. Frequent and mandatory training of healthcare students for an active shooter incident will improve their ability to make split-second decisions that could mean life or death for themselves, their patients, their colleagues, and others.

\section{References}

1. Adashi EY, Gao H, Cohen IG (2015) Hospital-Based Active Shooter Incidents; Sanctuary Under Fire. JAMA 313: 1209-1210.

2. (2014) U.S. Department of Health and Human Services, Office of the Assistant Secretary for Preparedness and Response, Incorporating Active Shooter Incident Planning into Health Care Facility Emergency Operations Plans, Washington, DC.

3. (2014) Experts advise hospitals to heed warning signs, leverage security to prepare against shootings. ED Manag 26: 97-101.

4. Kelen GD, Catlett CL, Kubit JG, Hsieh YH (2012) Hospital-based shootings in the United States: 2000 to 2011. Ann Emerg Med 60: 790-798.

5. Phelps S, Russell R, Doering G (2007) Model "code silver" internal lockdown policy in response to active shooters. Am J Disaster Med 2: 143-150.

6. Aksakal FN, Karaşahin EF, Dikmen AU, Avci E, Ozkan S (2015) Workplace physical violence, verbal violence, and mobbing experienced by nurses at a university hospital. Turk J Med Sci 45: 1360-1368.

7. Al-Omari H (2015) Physical and verbal workplace violence against nurses in Jordan. Int Nurs Rev 62: 111-118.

8. Yildirim A, Yildirim D (2007) Mobbing in the workplace by peers and managers: mobbing experienced by nurses working in healthcare facilities in Turkey and its effect on nurses. J Clin Nurs 16: 1444-1453.

9. Abou-ElWafa HS, El-Gilany AH, Abd-El-Raouf SE, Abd-Elmouty SM, ElSayed Rel-S (2015) J Interpers Violence 30: 857-872.

10. Zeng JY, An FR, Xiang YT, Qi YK, Ungvari GS, et al. (2013) Frequency and risk factors of workplace violence on psychiatric nurses and its impact on their quality of life in China. Psychiatry Res 210: 510-514. 
Citation: Rega PP, Fink BN (2016) Active Shooter Exercise Training for Nurses in Emergency Medicine. Adv Practice Nurs 1: 109. doi: 10.4172/2573-0347.1000109

Page 4 of 4

11. Jiao M, Ning N, Li Y, Gao L, Cui Y, et al. (2015) Workplace violence against nurses in Chinese hospitals: a cross-sectional survey. BMJ Open 5: e006719.

12. Speroni KG, Fitch T, Dawson E, Dugan L, Atherton M (2014) Incidence and cost of nurse workplace violence perpetrated by hospital patients or patient visitors. J Emerg Nurs. 40: 218-228.

13. Hamdan M, Hamra A (2015) Workplace violence towards workers in the emergency departments of Palestinian hospitals: a cross-sectional study. Hum Resour Health 13: 28.

14. Wada K, Suehiro Y (2014) Violence chain surrounding patient-to-staff violence in Japanese hospitals. Arch Environ Occup Health 69: 121-124.

15. Kwok RP, Law YK, Li KE, Ng YC, Cheung MH, et al. (2006) Prevalence of workplace violence against nurses in Hong Kong. Hong Kong Med J 12: 6-9.

16. Vezyridis P, Samoutis A, Mavrikiou PM (2015) Workplace violence against clinicians in Cypriot emergency departments: a national questionnaire survey. J Clin Nurse 24: 1210-1222.
17. Alkorashy HA, Al Moalad FB (2016) Workplace violence against nursing staff in a Saudi university hospital. Int Nurs Rev.

18. Kitaneh M, Hamdan M (2012) Workplace violence against physicians and nurses in Palestinian public hospitals: a cross-sectional study. BMC Health Serv Res 12: 469.

19. Mantzouranis G, Fafliora E, Bampalis VG, Christopoulou I (2015) Assessment and Analysis of Workplace Violence in a Greek Tertiary Hospital. Arch Environ Occup Health 70: 256-264.

20. Teymourzadeh E, Rashidian A, Arab M, Akbari-Sari A, Hakimzadeh SM. (2014) Nurses exposure to workplace violence in a large teaching hospital in Iran. Int J Health Policy Manag 3: 301-305.

21. United States Department of Justice (2013) A Study of Active Shooter Incidents in the United States between 2000 and 2013. 